\title{
Economically important dipteran species biodiversity in South Tripura district of Tripura
}

D. Sharmah*1, A. Khound ${ }^{2}$ and S. Rahman ${ }^{3}$

${ }^{1}$ Krishi Vigyan Kendra (ICAR), South Tripura (Tripura) India

${ }^{2}$ Krishi Vigyan Kendra, Baksa (Assam) India

${ }^{3}$ Assam Agricultural University, Jorhat (Assam) India

\section{ARITCLE INFO}

Received : 13.12 .2019

Revised : 05.03 .2020

Accepted : 18.03 .2020

\section{KEY WORDS :}

Biodiversity, Dipterans, Abundance,

Economic importance, South Tripura

*Corresponding author:

Email : dasharmah@gmail.com

\begin{abstract}
The present two years experimental survey was carried out for assessment of distribution pattern and diversity of different dipteran insects species in the South Tripura district of Tripura during 2015-16 and 2016-17. The various dipteran insects were collected from different localities of South Tripura district viz., Manumukh, Birchandra Manu, West pillak and Bedantra para. The selected areas for collection were varied from farmland to forest areas with an average elevation of 26 meters. During the study a total of 40 numbers of surveys were made and study reveals that the area under the survey has dipteran insects belonging to 18 families, 28 genera, and 55 species and among the collected 55 numbers of species the ecological roles span are ranges from vertebrate blood feeding to detritivory species.
\end{abstract}

How to view point the article : Sharmah, D., Khound, A. and Rahman, S. (2020). Economically important dipteran species biodiversity in South Tripura district of Tripura. Internat. J. Plant Protec., 13(1) : 71-75, DOI : 10.15740/HAS/IJPP/13.1/71-75, Copyright@ 2020: Hind AgriHorticultural Society. 